[Title Page]

A Shear Wall Element for Nonlinear Seismic Analysis of Super-Tall Buildings Using

$$
\text { OpenSees }
$$

Xinzheng Lu ${ }^{\mathrm{a}, *}$, Linlin Xie ${ }^{\mathrm{a}}$, Hong Guan', Yuli Huang ${ }^{\mathrm{c}}$, Xiao Lu ${ }^{\mathrm{d}}$

${ }^{\text {a }}$ Department of Civil Engineering, Tsinghua University, Beijing, P.R. China

${ }^{\text {b }}$ Griffith School of Engineering, Griffith University Gold Coast Campus, Queensland 4222,

Australia

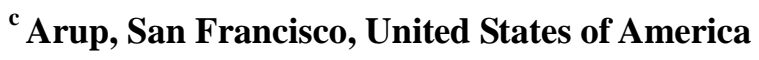

${ }^{d}$ Department of Civil Engineering, Beijing Jiaotong University, Beijing, P.R. China

Correspondence information:

Professor Xinzheng LU

Department of Civil Engineering, Tsinghua University, Beijing 100084, China

Telephone: +86-10-62795364

Email: luxz@tsinghua.edu.cn 


\title{
A Shear Wall Element for Nonlinear Seismic Analysis of Super-Tall Buildings
}

\author{
Using OpenSees \\ Xinzheng Lu ${ }^{\mathrm{a}, *}$, Linlin Xie ${ }^{\mathrm{a}}$, Hong Guan ${ }^{\mathrm{b}}$, Yuli Huang ${ }^{\mathrm{c}}$, Xiao Lu ${ }^{\mathrm{d}}$ \\ ${ }^{a}$ Department of Civil Engineering, Tsinghua University, Beijing, P.R. China \\ ${ }^{\mathrm{b}}$ Griffith School of Engineering, Griffith University Gold Coast Campus, Queensland 4222,
}

\author{
Australia \\ ${ }^{\mathrm{c}}$ Arup, San Francisco, United States of America \\ ${ }^{\mathrm{d}}$ Department of Civil Engineering, Beijing Jiaotong University, Beijing, P.R. China.
}

\begin{abstract}
Numerical simulation has increasingly become an effective method and powerful tool for performance-based earthquake engineering research. Amongst the existing research efforts, most numerical analyses were conducted using general-purpose commercial software, which to some extent limits in-depth investigations on specific topics with complicated nature. In consequence, this work develops a new shear wall element model and associated material constitutive models based on the open source finite element (FE) code OpenSees, in order to perform nonlinear seismic analyses of high-rise RC frame-core tube structures. A series of shear walls, a 141.8-m frame-core tube building and a super-tall building (the Shanghai Tower, with a height of $632 \mathrm{~m}$ ) are simulated. The rationality and reliability of the proposed element model and analysis method are validated through comparison with the available experimental data as well as the analytical results of a well validated commercial FE code. The research outcome will assist in providing a useful reference and an effective tool for further numerical analysis of the seismic behavior of tall and super-tall
\end{abstract}


buildings.

Key words: Frame-core tube; nonlinear analysis; OpenSees; multi-layer element; super-tall building; Shanghai Tower. 


\section{Introduction}

In recent years, research on seismic behavior of tall and super-tall buildings has become increasingly popular, due to rapid construction of this type of buildings and high frequency of earthquakes worldwide. Research to date indicates that numerical simulation is effective for nonlinear seismic analyses of such buildings [1-11], but most of the simulations were performed using various commercial finite element (FE) software packages. For example, based on the commercial FE code of MSC.Marc [12], Lu et al. [1-3] proposed a numerical model integrating fiber-beam elements, multi-layer shell elements and an element deactivation technique for collapse simulation of super-tall buildings induced by extreme earthquakes. Poon et al. [8] and Jiang et al. [9] used Perform 3D, a commercial software package widely used for the design and nonlinear analysis of structures, to evaluate the performance of super-tall buildings in earthquakes. Among others, Lu et al. [10] and Michaloudis et al. [11] used ABAQUS and LS-DYNA for nonlinear analyses of seismic capacity of buildings aimed at providing a guideline for practical designs. Despite these research efforts, limited work is available to examine and compare the existing numerical simulation results specific to super-tall buildings, which is a very important piece of information for validating the rationality and accuracy of these simulations. The primary reason of lacking such work is that a design agency or research institute can hardly be willing to purchase several commercial software packages with similar functionality. To overcome this limitation, a free open-source software program is an alternative to provide a useful resource to validate and improve the reliability of the numerical 
simulations of super-tall buildings through comparative analyses.

Existing commercial software packages offer many notable advantages, particularly in terms of computational stability and convenience of graphic user interfaces (GUI); yet there are several drawbacks. In addition to their high cost, the source codes of commercial software are usually unavailable, thus restricting further in-depth research and discussion on their internal mechanisms and functionalities. Furthermore, the secondary development functions of commercial software are strictly controlled, making it difficult to integrate the latest research outcomes into their source codes. The computational models established using commercial software also cannot be shared among the research community unless the same set of software is used by all research institutes. In contrast, an open-source software has the potential to be more beneficial because it is free of charge, all source codes are available and adding new modules into the codes is highly convenient.

For earthquake engineering research, several open source programs are available including OOFEM [13], and IDARC [14]. As an object-oriented open source FE software program for numerical simulation, the Open System for Earthquake Engineering Simulation (OpenSees) (http://opensees.berkely.edu) [15, 16] has increasingly become one of the most influential open platforms.

Unlike conventional commercial software, OpenSees is versatile; it incorporates various types of materials, elements, and powerful algorithms, thus allowing flexible definition of numerical models according to the requirements of different research projects. OpenSees is also extensible; it is organized with an advanced philosophy 
that is designed to sustainably integrate the latest research outcomes. Therefore, researchers are permitted and encouraged to get involved in the code development of OpenSees. Lastly, the open exchange environment enables reuse of previous achievements (including the structural numerical models) for the benefit of subsequent research activities. This effectively aids other researchers in reproducing existing research outcomes and in turn making their own contributions. Because of these advantages, OpenSees is adopted in this study to conduct a nonlinear seismic analysis of super-tall buildings.

Despite the abovementioned numerous advantages, there are two significant challenges in using OpenSees to perform such an analysis. The first and foremost challenge is that OpenSees lacks an appropriate and versatile numerical model for shear walls, one of the most important structural components in super-tall buildings [17]. Note that its existing fiber beam model is incapable of simulating complex mechanical behaviors of various types of shear walls. In contrast, such a simulation can be successfully performed using the multi-layer shell model, as demonstrated by several published research [1-6]. As such, it is necessary to develop a reliable and rigorous multi-layer shell model for OpenSees. The second challenge is that OpenSees has rarely been used to study the seismic behavior of large-scale, complicated structures. Therefore, further studies are required to investigate the modeling techniques, solution algorithms, and memory management of OpenSees to cover seismic analyses of complicated large-scale structures.

As described above, this research proposes and integrates a new shear wall model 
with associated material constitutive models in OpenSees. Simulations of various types of shear walls under pseudo-static loadings are performed. The simulation results are proven to agree well with the available experimental data, thus validating the rationality and reliability of the proposed multi-layer shell models. Note that the commercial FE codes of MSC.Marc has been widely used in nonlinear analyses of tall buildings and well validated in terms of rationality and accuracy $[1-6,18]$. In this study, comparisons between the simulation results of OpenSees and MSC.MARC are conducted, to further validate the proposed FE models and analytical strategies for tall buildings using OpenSees. To facilitate this, a conversion program, from MSC.Marc to OpenSees, is developed to promote the modeling efficiency and ensure consistency of the two analyses using both software packages. The selection of critical analysis algorithms and the determination of computational parameters are discussed in some detail. Specifically, the fiber beam and multi-layer shell elements [1-6] are used for nonlinear seismic analyses of a $141.8 \mathrm{~m}$ tall building and a $632 \mathrm{~m}$ super-tall building. Good agreement is also achieved between the analytical results of OpenSees and MSC.Marc. The research outcome of this study will assist in providing a useful reference and an effective tool for further research on the seismic behavior of super-tall buildings.

\section{Multi-layer shell element model for shear walls}

\subsection{Theoretical background of multi-layer shell element model}

The multi-layer shell formulation [1] is implemented in OpenSees using the "ShellMITC4" element, which is a four-node shell element based on the theory of 
mixed interpolation of tensorial components (MITC) proposed by Dvorkin et al. [19].

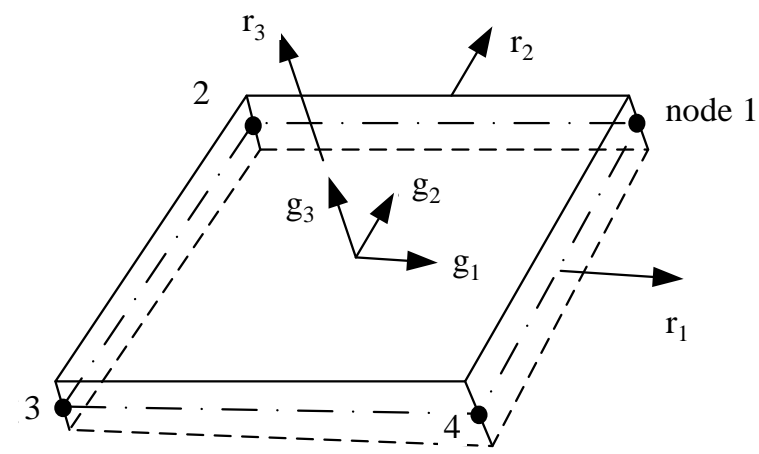

Fig. 1. Local Cartesian coordinate system

Fig. 1 illustrates the local coordinate system adopted for the shell element. Vector $\mathrm{r}_{1}$ extends from the midpoint of Nodes 2 and 3 to the midpoint of Nodes 1 and 4 . Vector $r_{2}$ extends from the midpoint of Nodes 3 and 4 to the midpoint of Nodes 1 and 2. The Gram-Schmidt orthonormalization is then adopted to adjust Vector $r_{2}$. Finally, Vector $r_{3}$ is determined as the cross product of Vectors $r_{1}$ and $r_{2}$ following the right hand rule. Vectors $g_{1}, g_{2}$ and $g_{3}$ are obtained through vector unitization of Vector $r_{1}$, orthogonal Vector $r_{2}$ and Vector $r_{3}$, respectively. The strains and curvatures at the in-plane integration points are obtained from the interpolation of the nodal displacements and rotations. When large deformations are taken into consideration, the coordinate system is updated based on the current coordinates of the nodes.

For each of the in-plane integration points, a layered/composite integrated section is then implemented to account for the nonlinear behavior of reinforced concrete (RC). The layered element simplifies the three-dimensional nonlinear behavior of the shear walls into a shell situation by discretizing them into several fully-bonded layers in the 
thickness direction. Different material properties and thicknesses can be assigned to each layer according to the size of the wall and the distribution of reinforcing bars, as illustrated in Fig. 2. The bars are smeared into one or more orthotropic layers according to their physical location and direction, as shown in Fig. 3. The stresses over a layer thickness are assumed to be consistent with those at the mid-surface of that layer. Therefore, if the shear wall is subdivided into sufficient number of layers, the multi-layer shell element can reasonably simulate the actual stress distribution over the thickness of the wall [20-21].

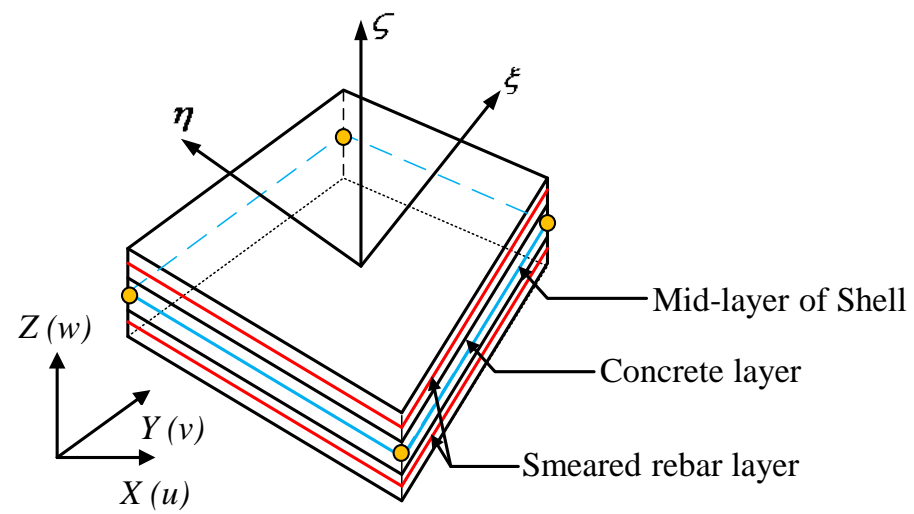

Fig. 2. Multi-layer shell element

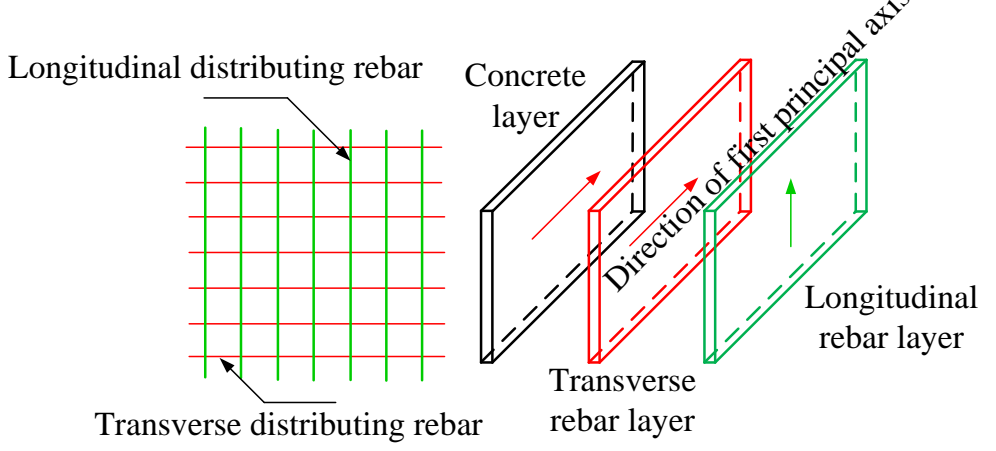

Fig. 3. Distribution of the rebar layer

The nonlinear behavior of concrete cracking, crushing and aggregate interlocking is 
incorporated in the planar concrete constitutive model. For steel reinforcement, the nonlinear behavior of yielding and the Bauschinger effect are taken into consideration in its uniaxial model.

In the multi-layer shell element, the axial strains and curvature of the middle layer are initially calculated; the strains of each layer are then obtained based on the plane-section assumption. The stresses of each integration point on each layer are subsequently calculated in accordance with the constitutive model of the corresponding layer. Lastly, the internal forces are calculated using the standard numerical integration method.

The multi-layer shell element has been proven to be a suitable model that can well capture the coupled in-plane/out-of-plane bending as well as the in-plane direct shear and coupled bending/shear behavior of the RC shear walls [1, 6, 20-22].

\subsection{Two-dimensional material constitutive model}

Concrete is assumed to be in a state of planar stress in the multi-layer shell element. An appropriate, reliable and robust two-dimensional concrete constitutive model is required to cater for the complicated mechanical behavior of shear walls and core tubes induced by an earthquake. The analytical model for concrete proposed in this research is based on the concept of damage mechanics and the smeared crack model. Cracks are assumed to form when the principal tensile stress exceeds the specified concrete tensile strength. Once cracking occurs, concrete is then treated as an orthotropic material. The shear stiffness deterioration (in terms of the reduced shear moduli obtained by multiplying the shear retention factor) is incorporated due to the 
effects of aggregate interlocking. Being simple in formulation, this analytical model also demonstrates a good stability in computation [21, 22].

The constitutive equation (Eq. 1) of concrete is expressed as follows:

$$
\sigma_{c}{ }^{\prime}=\left[\begin{array}{cc}
1-d_{1} & \\
& 1-d_{2}
\end{array}\right] D_{e} \varepsilon_{c}
$$

where $\sigma_{c}$ and $\varepsilon_{c}$ 'represent the stress and strain tensors, respectively, in the principal stress coordinate system before cracking or in the crack coordinate system after cracking. $D_{e}$ is the elastic constitutive matrix, and $d_{1}$ and $d_{2}$ are the damage parameters, which can be respectively calculated by the damage evolution curves under tension as recommended by Løland [23] and under compression as suggested by Mazars [24].

After cracking, the relationship between the shear stress $\tau$ and shear strain $\gamma$ in the crack coordinates is as follows:

$$
\tau=\beta G \gamma
$$

where $G$ is the elastic shear modulus and $\beta$ is the shear retention factor to account for the shear stiffness deterioration after cracking occurs [25].

Both Eqs. 1 and 2, formulated with either the principal stress coordinate or the crack coordinate, must be transformed to a global coordinate system [26] following Eq. 3.

$$
\left\{\begin{array}{l}
D=R^{T} D^{\prime} R \\
R=\left[\begin{array}{ccc}
\cos ^{2} \theta & \sin ^{2} \theta & \cos \theta \sin \theta \\
\sin ^{2} \theta & \cos ^{2} \theta & -\cos \theta \sin \theta \\
-2 \cos \theta \sin \theta & 2 \cos \theta \sin \theta & \cos ^{2} \theta-\sin ^{2} \theta
\end{array}\right]
\end{array}\right.
$$

where $D$ and $D^{\prime}$ are the constitutive matrices in the global and local coordinates, 
respectively. $R$ is the transformation matrix and $\theta$ is the angle between the global and local coordinates.

The reinforcing bars are simulated as smeared steel layers of equivalent thicknesses. The material model for reinforcing steel, designated as PlateRebar, is derived from the uniaxial materials for rebars [15] in conjunction with their corresponding angles. Detailed information can be found in Appendix A.

\section{Implementation and validation of the multi-layer shell element}

\subsection{Implementation of the model in OpenSees}

The multi-layer shell element incorporating the two-dimensional material constitutive models is implemented in the latest version 2.4.4 of OpenSees (http://opensees.berkeley.edu/), as shown in Fig. 4(a). The overall procedure for defining the multi-layer shell element in OpenSees is illustrated in Fig. 4(b), and the corresponding command line scripts are given in Appendix A.

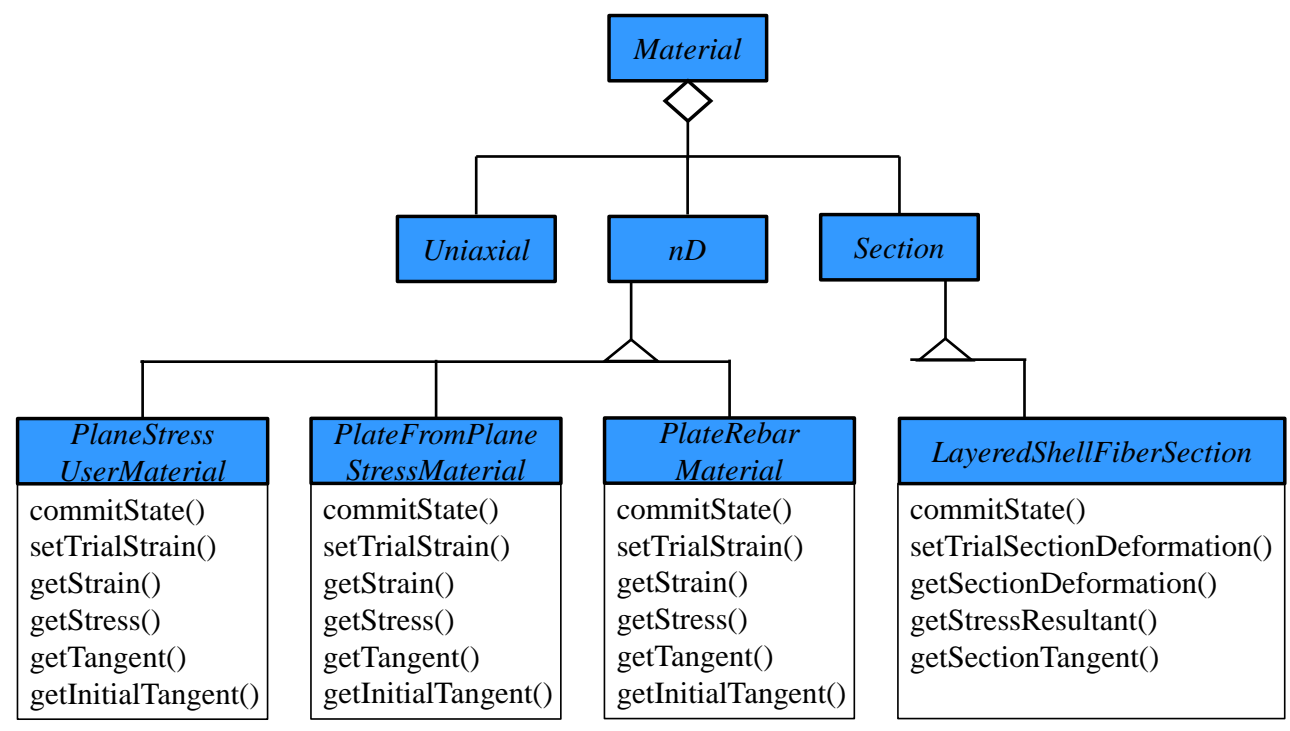

(a) Material classes 


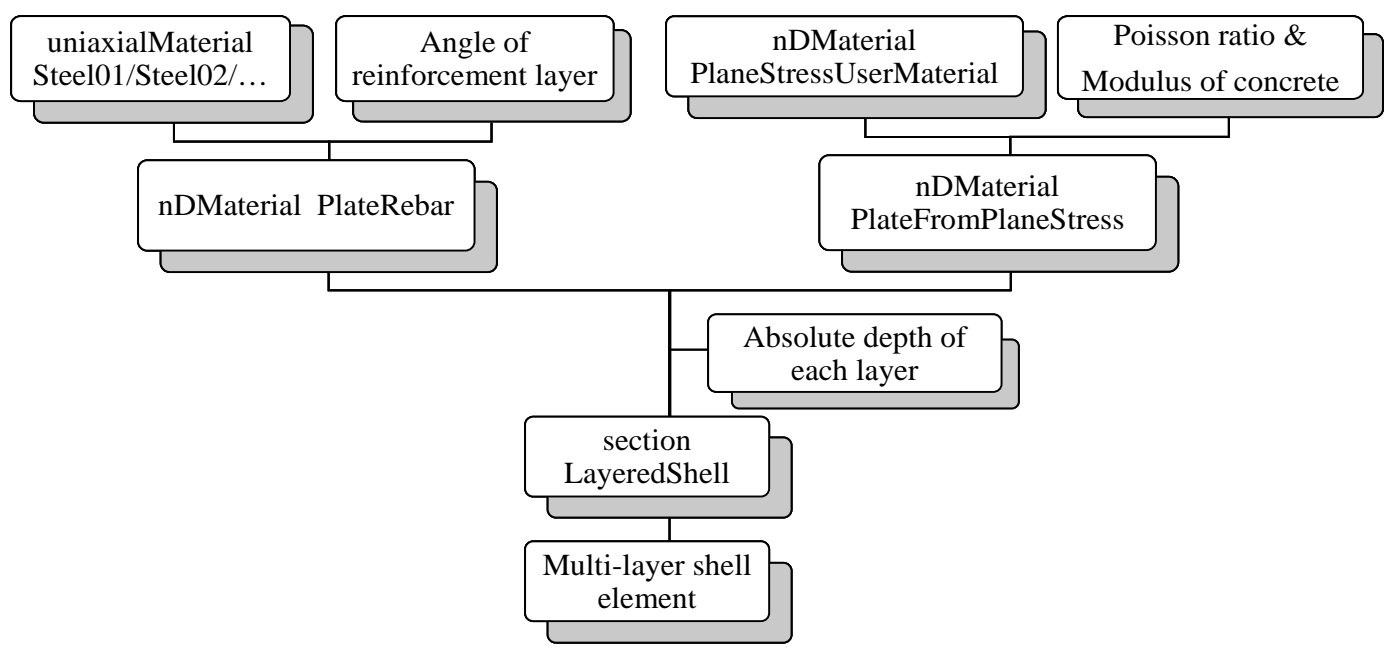

(b) Overall procedure for defining the multi-layer shell element

Fig. 4. Framework of the multi-layer shell element

\subsection{Finite element discretization}

Finite element discretization (i.e., the element size) has a direct impact on the accuracy of the analysis solutions. This study adopts the popularly used crack band theory proposed by Bazant $[27,28]$, in order to eliminate the size effect. To achieve this, the slope of the softening branch of cracked concrete is proportionally adjusted according to the element size, leading to identical fracture energy for all elements. To verify the effectiveness of the crack band theory, a typical rectangular wall panel SW1-1 tested by Lu et al. [29] is discretized with three different mesh sizes (40, 160 and 360 elements), as shown in Fig. 5 (a-c). The experimental and simulation results are compared in Fig. 6 with close agreement. This comparison indicates that the effect of mesh size on the predicted behavior can be effectively eliminated using the crack band theory, and little improvement can be achieved by introducing additional nodes and elements. In consequence, the crack band theory is recommended and adopted in the following study of both shear walls and super-tall buildings. 


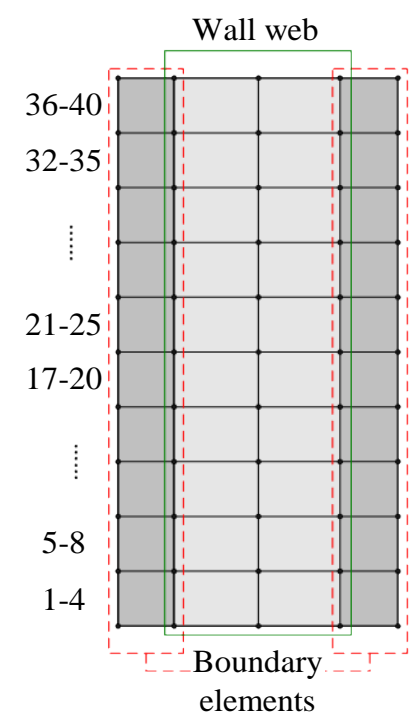

(a) 40 elements

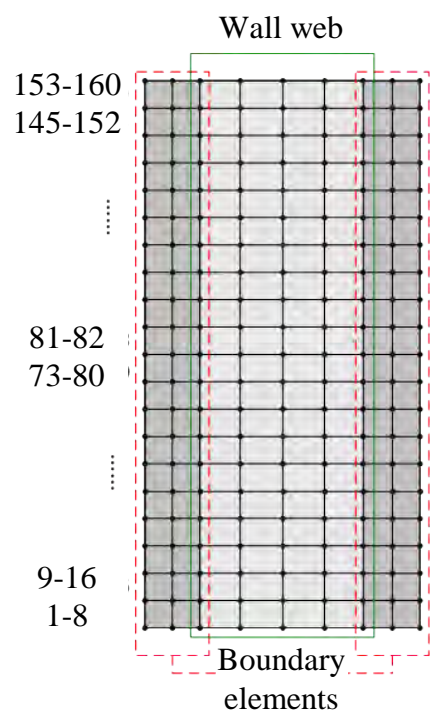

(b) 160 elements

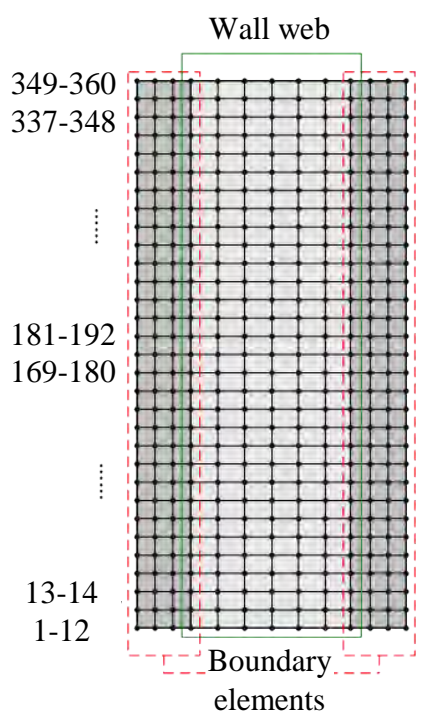

(c) 360 elements

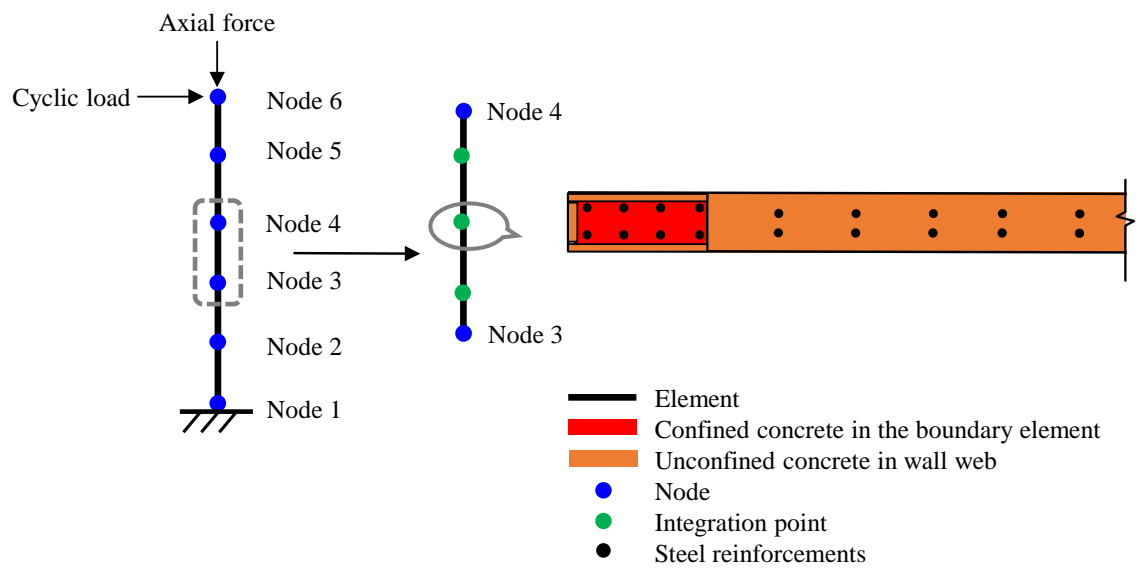

(d) Fiber model

Fig. 5. Finite element meshes for SW1-1

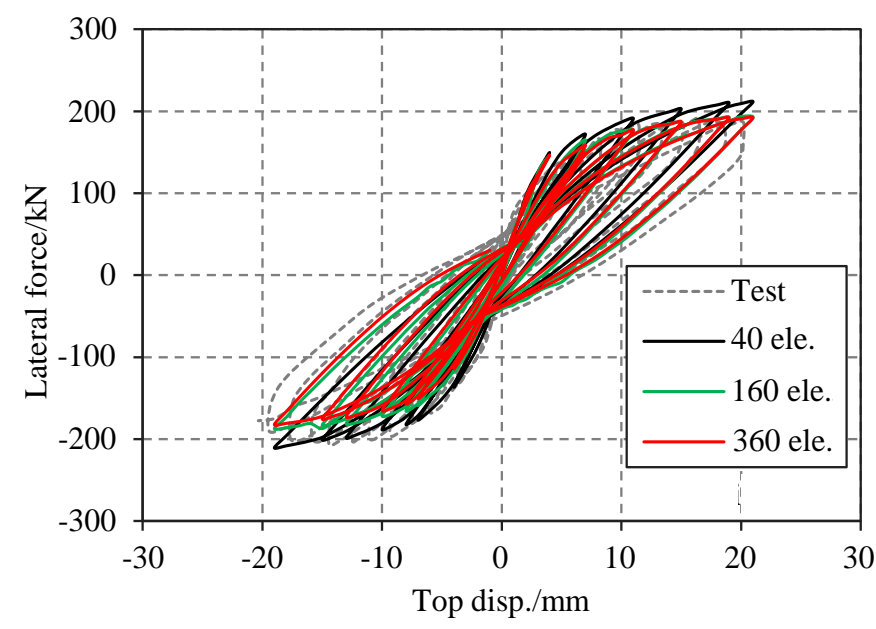

Fig. 6. Mesh size effect on the analysis results 


\subsection{Validation of the model with a series of test results}

To validate the reliability and accuracy of the proposed model, a series of 12 rectangular walls [29] with different axial load ratios, aspect ratios, boundary element widths, reinforcement ratios and stirrup ratios in boundary elements are simulated initially. To further validate the versatility of the model, six shear walls with different sections (i.e., an H-shaped wall, T-shaped wall [30], coupled wall [31] and symmetric double short-limb walls [32]) are also simulated.

To compare the performance of the multi-layer shell element and the traditional fiber beam model for shear walls, both are used to simulate the rectangular, H-shaped and T-shaped walls. This comparison reveals that to simulate twin walls connected by coupling beams, the multi-layer shell model is much easier to use than the fiber beam modeling. In consequence, only the multi-layer shell model is adopted to simulate the coupled walls. For other types of walls including rectangular and flanged shear walls, on the other hand, both the multi-layer shell element and the fiber beam model can be adopted. The differences in their respective modelling strategies are discussed below.

When using the fiber beam model, the shear walls are modeled with five non-linear beam-column elements using the compliance method and each element has five integration points [17], as shown in Fig. 5(d). The concrete fibers in the fiber section are assumed to follow the Kent-Scott-Park stress-strain model and the corresponding hysteretic rules available in OpenSees through Concrete01 [15]. The confinement model proposed by Mander et al. [33] is adopted to calculate the characteristic parameters of the unconfined and confined concrete. The stress-strain model proposed 
by Filippou et al. [34] known as Steel02 in OpenSees is used to simulate the steel reinforcement.

As for the multi-layer shell model, the vertical steel reinforcement within the wall web and all the stirrups are smeared into one or more layers, while the longitudinally concentrated steel reinforcement within the boundary elements are simulated with truss elements that are incorporated into the shell element by sharing the same nodes. Taking into account the out-of-plane mechanical behavior, the flanges (out-of-plane) and webs (in-plane) of the $\mathrm{H}$ - or T-shaped walls are both simulated using the multi-layer shell elements. The characteristic parameters of concrete and steel reinforcements are determined from the tensile tests of rebars and the compressive tests of standard concrete cylinders or cubes. Specifically, based on the compressive strength of concrete, the characteristic parameters of both unconfined concrete in wall webs and confined concrete in boundary elements are calculated using the concrete constitutive model proposed by Mander et al. [33]. The tensile strength, elastic modulus and fracture strain obtained from the tensile tests of rebars are used to determine the characteristic parameters of reinforcements. A comparison between the experimental yield load, yield displacement and peak load and the simulation results, including the results using the multi-layer shell elements and fiber elements, is presented in Table 1. It is evident that the majority of the predictions using the multi-shell element agree well with the experimental data, thus validating the reliability and versatility of the multi-layer shell element. 


\section{Table 1}

Comparison between the experimental and the simulated results of the shear walls

\begin{tabular}{|c|c|c|c|c|c|c|c|c|c|}
\hline & \multirow[t]{2}{*}{$\begin{array}{l}\text { Specimen } \\
\text { no. }\end{array}$} & \multirow[t]{2}{*}{$\begin{array}{l}\text { Aspect } \\
\text { ratio }\end{array}$} & \multirow[t]{2}{*}{$\begin{array}{c}\text { Axial } \\
\text { load } \\
\text { ratio }\end{array}$} & \multicolumn{2}{|c|}{$\begin{array}{c}\text { Error in } \\
\text { yield load } \\
(\%)\end{array}$} & \multicolumn{2}{|c|}{$\begin{array}{c}\text { Error in yield } \\
\text { disp. (\%) }\end{array}$} & \multicolumn{2}{|c|}{$\begin{array}{c}\text { Error in } \\
\text { peak load } \\
(\%)\end{array}$} \\
\hline & & & & shell & fiber & shell & fiber & shell & fiber \\
\hline \multirow{12}{*}{$\begin{array}{l}\text { Rectangular } \\
\text { walls [29] }\end{array}$} & SW1-1 & 2.0 & 0.1 & 2.3 & 1.6 & 6.4 & -10.2 & -3.1 & -3.4 \\
\hline & SW1-2 & 2.0 & 0.2 & 0.8 & 0.6 & 0 & -1.3 & -1.5 & -6.2 \\
\hline & SW1-3 & 2.0 & 0.3 & 25 & 18.4 & 9.6 & -13.1 & -4.5 & 2.3 \\
\hline & SW1-4 & 2.0 & 0.4 & 27 & 18.1 & 11 & -16.2 & 10.2 & 0.4 \\
\hline & SW2-1 & 1.0 & 0.3 & 3.6 & 11.2 & 1.2 & -25 & 9.6 & -14 \\
\hline & SW2-2 & 1.5 & 0.3 & 19.3 & 31 & 5.6 & -18 & 1.2 & -5.8 \\
\hline & SW4-1 & 2.0 & 0.3 & 7.9 & 8.6 & 2.4 & -3.2 & 2.9 & -3.6 \\
\hline & SW4-2 & 2.0 & 0.3 & 4.6 & 5.4 & 2.9 & -2.1 & 8.4 & 7.8 \\
\hline & SW5-1 & 2.0 & 0.3 & 2.6 & 3.1 & 1.5 & -2.3 & 2.1 & 0 \\
\hline & SW5-3 & 2.0 & 0.3 & -2.2 & 1.3 & 2.3 & -1.7 & 2.2 & -1.8 \\
\hline & SW6-1 & 2.0 & 0.3 & 20.1 & 8.1 & 3.2 & -2.1 & 5.5 & 0 \\
\hline & SW6-3 & 2.0 & 0.3 & 9.6 & 6.2 & 2.8 & -1.2 & -1.4 & -0.8 \\
\hline Flange walls & SW-3 & 1.9 & 0.26 & 1.3 & 1.5 & -4.5 & -7.3 & 10 & -6.4 \\
\hline [30] & SW-4 & 1.9 & 0.26 & 8.6 & 12.3 & 5.7 & -15 & 4.3 & 8.9 \\
\hline $\begin{array}{c}\text { Coupled wall } \\
\text { [31] }\end{array}$ & CW-3 & - & - & -1.6 & - & 0.6 & - & 7.4 & - \\
\hline Symmetric & SW1-1 & - & - & 9.6 & - & 0 & - & 12.9 & - \\
\hline double & SW1-2 & - & - & 11.2 & - & 0 & - & -5.8 & - \\
\hline $\begin{array}{l}\text { short-limb } \\
\text { walls [32] }\end{array}$ & SW1-3 & - & - & 10.5 & - & 0 & - & 9.4 & - \\
\hline
\end{tabular}

Amongst the 18 shear walls given in Table 1, only four typical ones are discussed in detail in this article, the dimensions and reinforcement details obtained from corresponding tests are illustrated in Fig. 7. The comparisons between the simulation results and experimental data on the lateral force-top displacement hysteretic curves of the selected shear walls are presented in Fig. 8. 


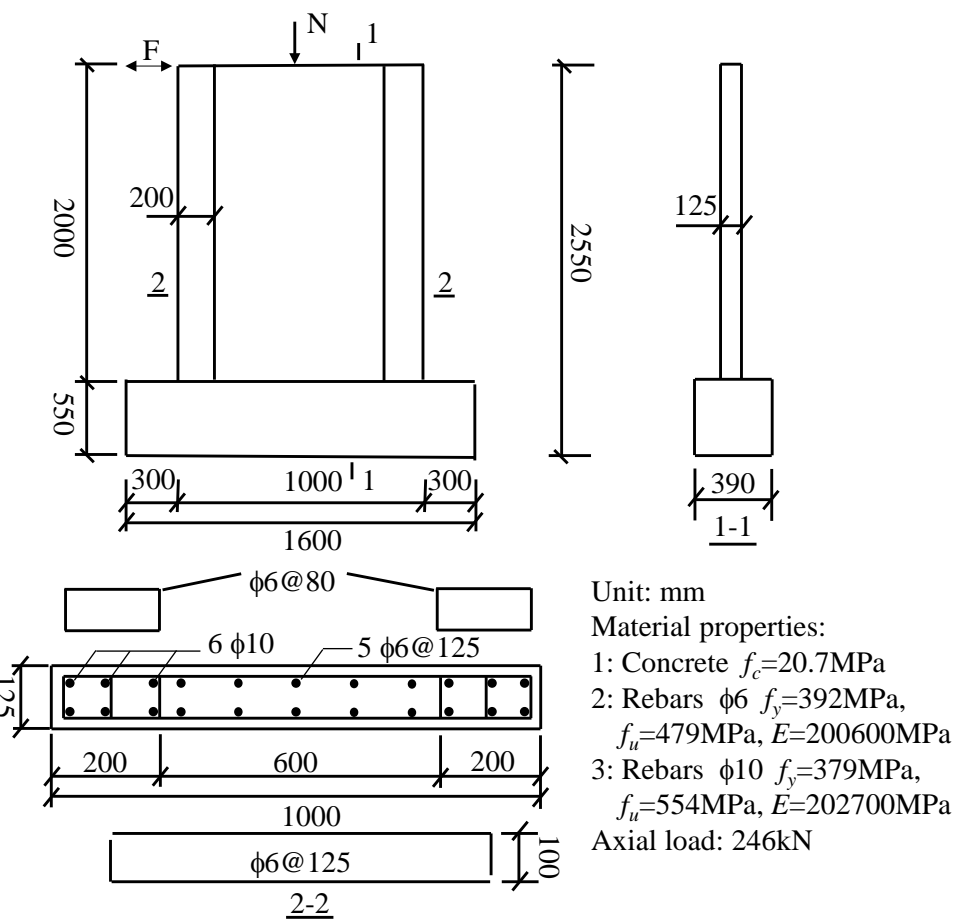

(a) SW1-1 [29]
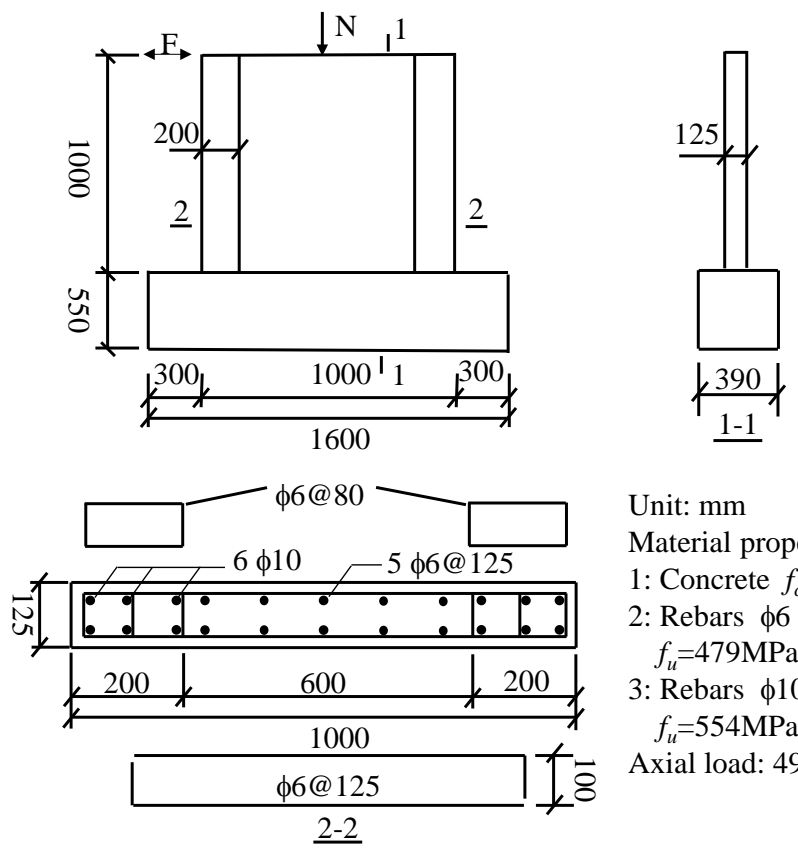

Unit: $\mathrm{mm}$

Material properties:

1: Concrete $f_{c}=30.8 \mathrm{MPa}$

2: Rebars $\phi 6 f_{y}=392 \mathrm{MPa}$, $f_{u}=479 \mathrm{MPa}, E=200600 \mathrm{MPa}$ 3: Rebars $\phi 10 f_{y}=379 \mathrm{MPa}$, $f_{u}=554 \mathrm{MPa}, E=202700 \mathrm{MPa}$ Axial load: $493 \mathrm{kN}$

(b) SW2-1 [29] 

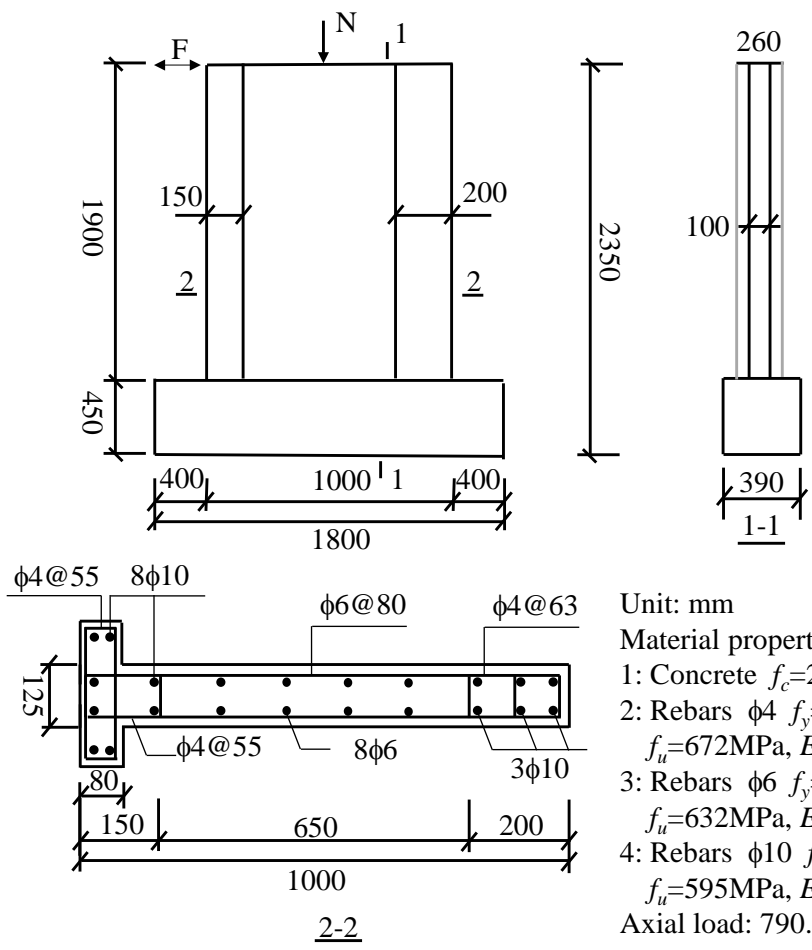

Unit: mm

Material properties:

1: Concrete $f_{c}=26.1 \mathrm{MPa}$

2: Rebars $\phi 4 f_{y}=632 \mathrm{MPa}$,

$f_{u}=672 \mathrm{MPa}, E=209000 \mathrm{MPa}$

3: Rebars $\phi 6 f_{y}=452 \mathrm{MPa}$,

$f_{u}=632 \mathrm{MPa}, E=200000 \mathrm{MPa}$

4: Rebars $\phi 10 f_{y}=395 \mathrm{MPa}$,

$f_{u}=595 \mathrm{MPa}, E=194000 \mathrm{MPa}$

Axial load: $790.8 \mathrm{kN}$

(c) SW-4 [30]

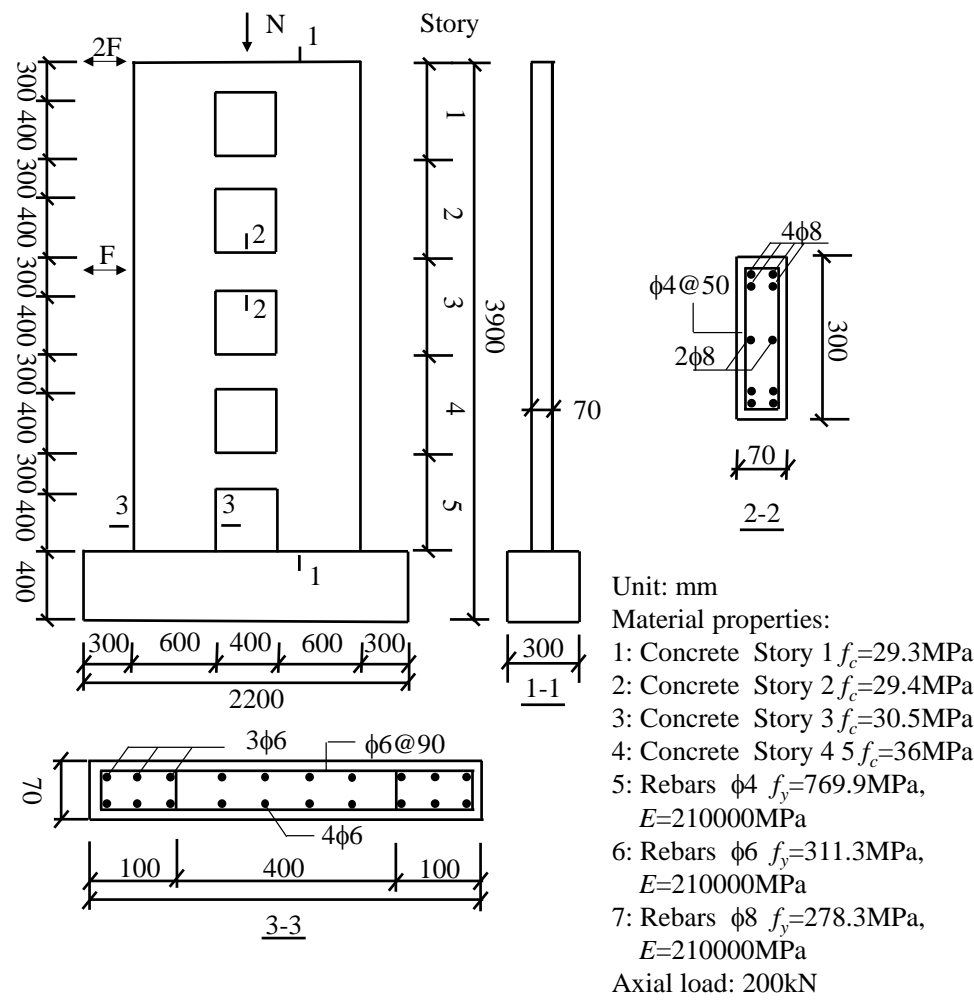

(d) CW-3 [31]

Fig. 7. Specimen dimensions and reinforcement details 
For rectangular walls with sufficient stirrups and moderate aspect ratios such as SW1-1 in Fig. 8(a), both the fiber beam model and the multi-layer shell model can well capture the characteristic behaviors of shear walls predominately governed by flexural behavior. In contrast, for specimens exhibiting shear behavior such as SW2-1 in Fig. 8(b), the multi-layer shell model better predicts the experimental data than the fiber beam model.

The flange wall presented in Fig. 8(c) is also dominated by flexural behavior. Due to relatively small flanges, both the fiber element and the multi-layer shell models can accurately capture the characteristic behavior, which also validates the reliability of the modeling approach for flange walls with shell elements.

For the coupled shear wall, CW-3 shown in Fig. 8(d), the hysteretic load-displacement relation curve predicted by the multi-layer shell element model only also agrees well with the experimental data.

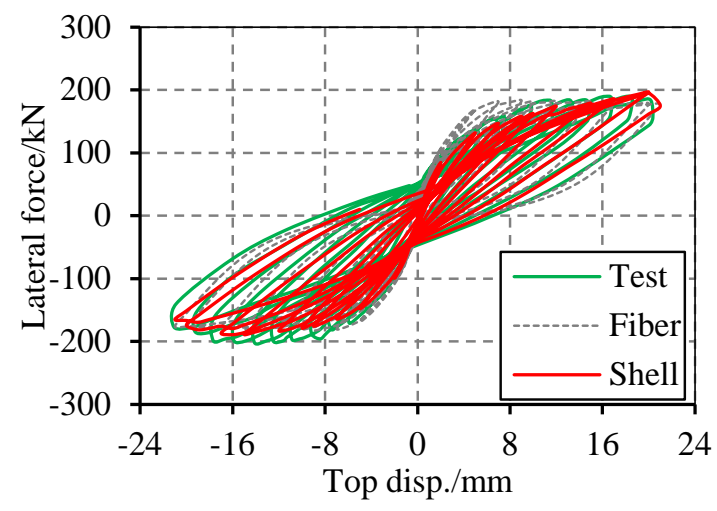

(a) SW1-1 [29] 


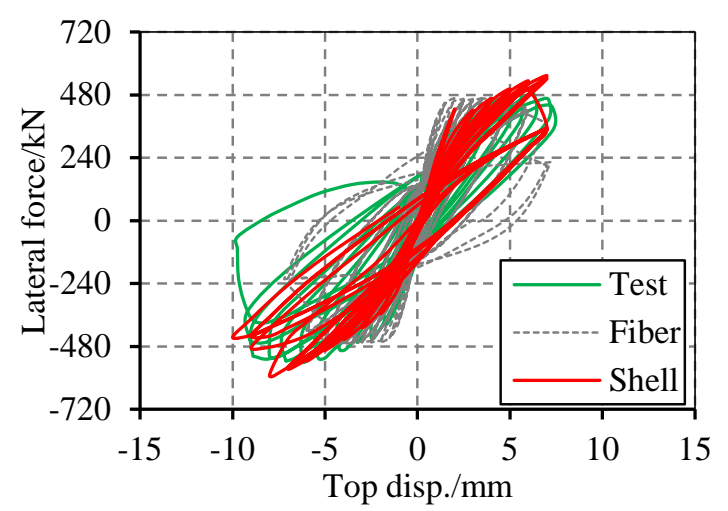

(b) SW2-1 [29]

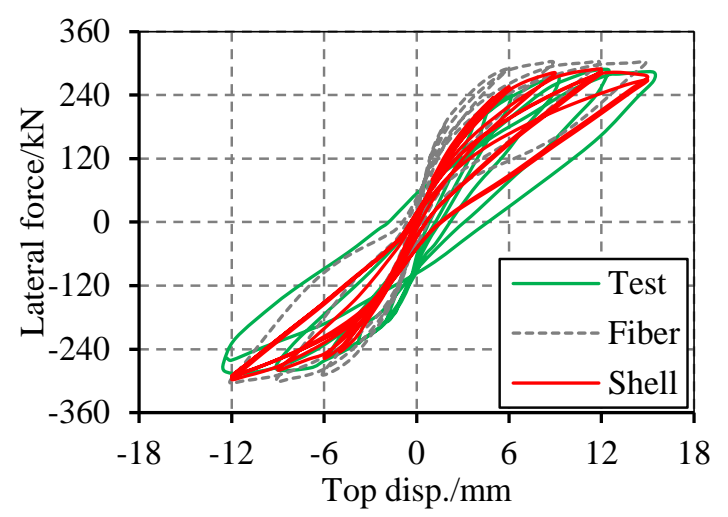

(c) SW-4 [30]

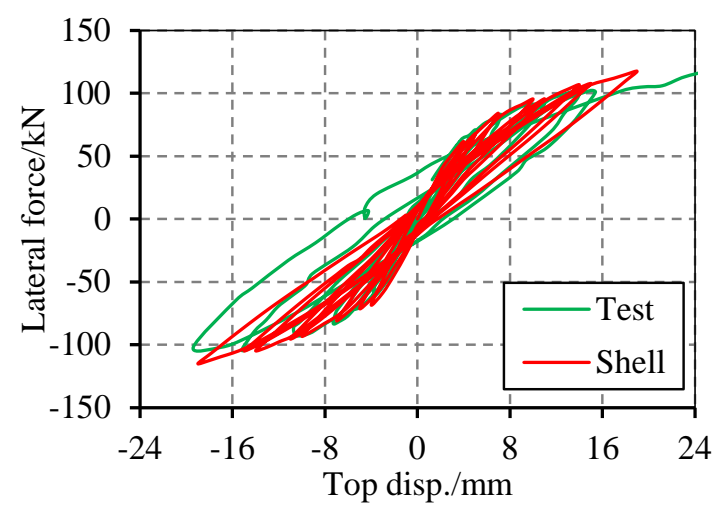

(d) $\mathrm{CW}-3[31]$

Fig. 8. Lateral force versus top displacement hysteretic curves of specimens

Based on the above, it can be concluded that the multi-layer shell element developed in OpenSees is capable of replicating the complex behavior of various types of shear walls. 
4 Modeling techniques and selection of analysis domain for super-tall buildings

\subsection{Modeling techniques}

In modeling a super-tall building, the fiber beam element based on the direct stiffness method, i.e., the DispBeamColumn element in OpenSees, is adopted to simulate the beams and columns [35]. The multi-layer shell element is used to simulate the shear walls, core tubes, coupling beams and slabs. For these elements, similar element discretization strategies and identical calculation methods for characteristic material parameters as mentioned above are adopted.

The absence of a graphical user interface (GUI) makes it difficult to establish and evaluate a complicated super-tall building model in OpenSees. In consequence, a conversion program, from MSC.Marc (which has a convenient GUI) to OpenSees, is developed to promote the modeling efficiency. Note that in this conversion program, the fiber beam elements and the multi-layer shell elements used in the MSC.Marc model are converted to the OpenSees model either fiber-by-fiber or layer-by-layer to ensure consistency of these two models and the subsequent analysis. This conversion facilitates convenient and reliable validation of the OpenSees simulation results with those of MSC.Marc. The corresponding conversion relationship is illustrated in Fig. 9.

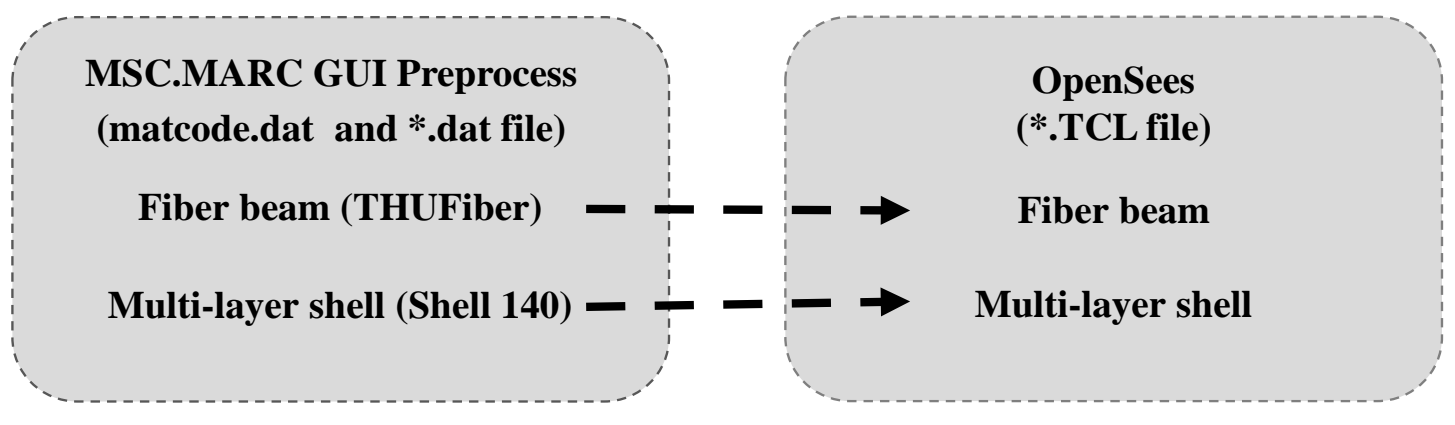

Fig. 9. Conversion relationship of "MARC to OpenSees" 


\subsection{Selection of analysis domain in OpenSees}

The analysis domain in OpenSees is an object composed of several component objects, including the Constraint Handler (determines how the constraint equations are enforced in the analysis), solution Algorithm, System of Equations (constructs a solver to store and solve the system of equations in the analysis) and Eigenvalue Solver (conducts eigenvalues analysis) [15]. Selection of these component objects determines the feasibility, stability and efficiency of the simulation [16]. Note that previous research [36-39] primarily focused on specimens and small-scale structures, and limited work is available on the selection of the analysis domain for large-scale structures. Note also that, the selected component objects suitable for small structures may not be applicable or efficient for large-scale structures. When conducting a nonlinear analysis of super-tall buildings in this study, most solvers and numerical algorithms are found to be ineffective in large-scale computations. Through a series of analyses of super-tall buildings, some efficient component objects are proposed as presented in Table 2.

\section{Table 2}

Recommendations of analysis domain

\begin{tabular}{ccc}
\hline $\begin{array}{c}\text { The command to assign } \\
\text { boundary constraints }\end{array}$ & $\begin{array}{c}\text { The command to assign a } \\
\text { matrix solver }\end{array}$ & $\begin{array}{c}\text { The command to assign } \\
\text { an eigen value solver }\end{array}$ \\
\hline Transformation & SparseSYM and CuSP & ProfileSPD \\
\hline
\end{tabular}

As for a Constraint Handler, the transformation method [15, 16] performs well in the following analyses of super-tall buildings. Due to their stability and efficiency, the solvers for sparse systems are recommended for the System of Equations command 
instead of those for band or profile systems. In particular, the solvers for the sparse symmetric system (i.e., SparesSYM and CuSP) are recommended. To conduct an eigenvalue analysis, the solver for a symmetric positive definite profile (i.e., ProfileSPD) is suggested.

\section{Nonlinear dynamic analysis of super-tall buildings}

\subsection{A forty-two story RC frame-core tube building}

\subsubsection{Overview of the structure}

To evaluate and improve the performance-based seismic design of tall buildings, the Pacific Earthquake Engineering Research Center (PEER) launched the Tall Buildings Initiative (TBI) research program. One of the case study buildings investigated in this program is Building 2A, a 42-story RC frame-core tube structure with a total above ground height of $141.8 \mathrm{~m}$ [40]. Based on the design information of Building 2A, a new building named Building 2N was redesigned by $\mathrm{Lu}$ et al. [41] according to the Chinese building design codes. A three-dimensional view and floor plan of Building 2N are shown in Fig. 10. Specific design details can be found in Lu et al. [41]. 


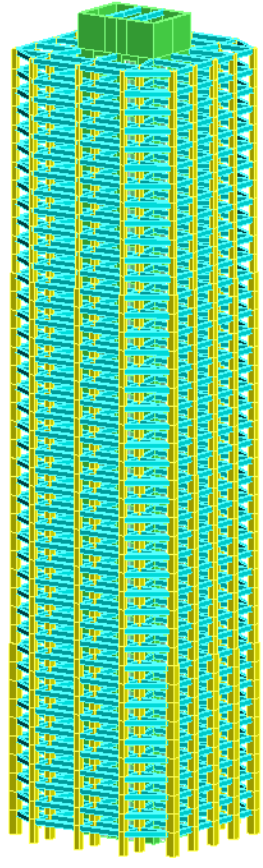

(a) Elevation

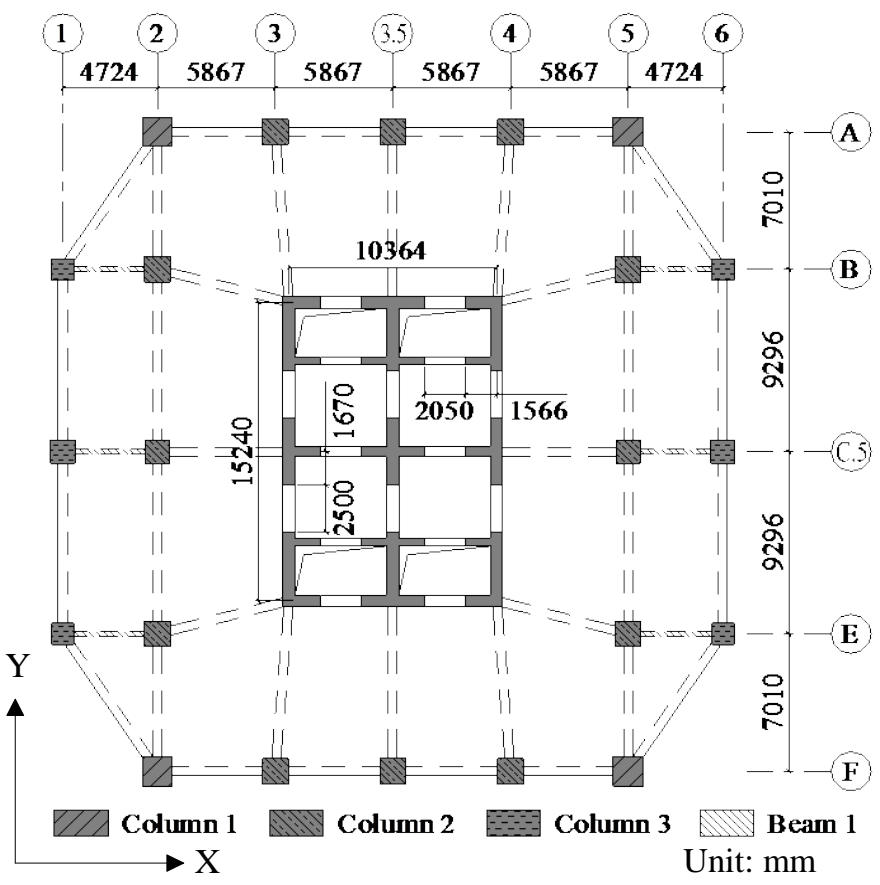

(b) Layout

Fig. 10. Details of Building 2N

The entire model of Building 2N, including 8,469 nodes, 9,744 fiber beam elements defined by 8,244 RC fiber sections and 4,704 multi-layer shell elements defined by 177 shell sections, was initially constructed in MSC.Marc and subsequently converted to OpenSees. The OpenSees model is freely assessable [42], which can be conveniently shared and reused in the research community.

It is very difficult to validate a numerical model for such a tall building by means of experiment. The reliability of the model can however be verified through comparisons between the analytical results of OpenSees and MSC.MARC. This is because MSC.Marc has been widely used in nonlinear analyses of tall buildings and adequately validated in terms of rationality and accuracy [1-6, 18].

\subsubsection{Basic dynamic properties}


A gravity analysis and a modal analysis are conducted prior to the nonlinear analysis. A comparison between the fundamental periods predicted by MSC.Marc and OpenSees is presented in Table 3. The results indicate a strong agreement in the basic dynamic properties, which validates the rationality of the model at the elastic stage.

\section{Table 3}

Comparison of the periods predicted by OpenSees and MSC.Marc

\begin{tabular}{cccc}
\hline & Marc & OpenSees & Relative error \\
\hline$T_{1}$ (1st-order translation in $X$ direction) & $1.791 \mathrm{~s}$ & $1.815 \mathrm{~s}$ & $1.3 \%$ \\
$T_{2}$ (1st-order translation in $Y$ direction) & $1.580 \mathrm{~s}$ & $1.579 \mathrm{~s}$ & $0.06 \%$ \\
$T_{3}$ (1st-order torsion) & $0.900 \mathrm{~s}$ & $0.890 \mathrm{~s}$ & $1.1 \%$ \\
\hline
\end{tabular}

\subsubsection{Pushover analysis}

The inverted triangular distribution of lateral load pattern is adopted to initiate the pushover analysis using both software packages. It is worth mentioning that the $P-\Delta$ effects are considered in the pushover analysis and the subsequent dynamic analysis. The base shear force versus the roof displacement and the distribution of inter-story drift ratios are plotted in Fig. 11 and Fig. 12, respectively. Good agreements are evident between the MSC.Marc and OpenSees predictions. The slight discrepancy is attributable to different concrete models adopted by these two packages. While both employ the smeared crack model, the multi-shell element implemented in OpenSees is based on damage mechanics whereas that in MSC.Marc is based on plastic mechanics. Nonetheless, the differences between the two simulation results are considered acceptable. 


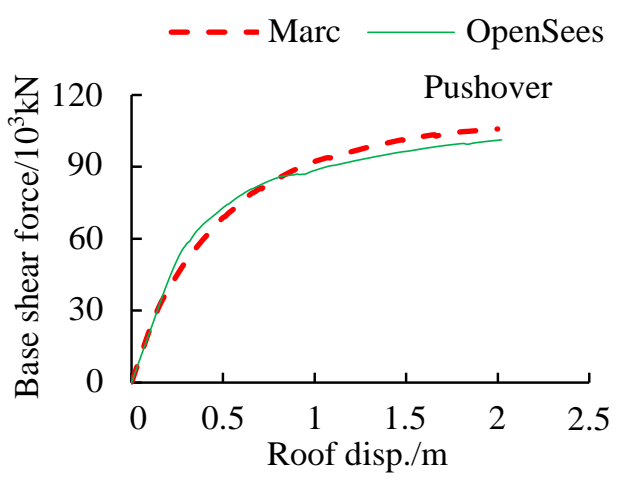

Fig. 11. Comparison of the base shear force- roof displacement curves

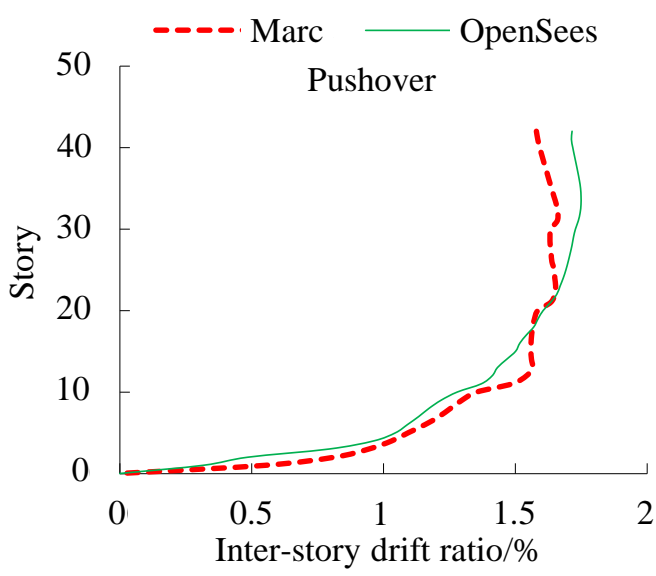

Fig. 12. Comparison of the inter-story drift ratio distribution

\subsubsection{Nonlinear dynamic analysis}

The ChiChi ground motion, which is scaled to a value of peak ground acceleration (PGA) of 110 gal and 300 gal according to the Chinese Code, is initially used as the seismic input to the structure along the $\mathrm{X}$-axis after the gravity analysis is conducted. To study the strong nonlinear behavior of Building $2 \mathrm{~N}$ under an extreme earthquake, a dynamic analysis with a PGA $=1000$ gal is also performed. During the nonlinear dynamic time-history analysis, a 5\% damping ratio suggested in Section 5.3 .4 of the Specification for the Design of Steel-Concrete Hybrid Structures in Tall Buildings (CECS 230; 280) [43] is adopted. Considering the contribution of higher-order modes 
to the seismic response of tall buildings, the $1^{\text {st }}$ and $9^{\text {th }}$ modes are chosen to calculate the coefficients of Rayleigh damping which is recommended by Chopra for most practical analyses [44]. The comparisons of the time-history curves of the roof are shown in Figures 13(a)-(c). In addition, the El-Centro and Northridge ground motions, which are scaled to PGA=1000 gal, are also adopted to conduct the dynamic analysis. The time-history curves of the roof are compared in Figures 13(d)-(e). The envelope of inter-story drift curves under the Northridge ground motion is presented in Fig. 13(f) because it has the maximum inter-story drift ratio amongst the three ground motions. Roof displacements represent the overall response of the entire structure which is non-sensitive to the local damage occurred on each story. In contrast, inter-story drift ratios are more sensitive. Due to different concrete constitutive models adopted by OpenSees and MSC.Marc, some discrepancies do exist between the local damage predictions of these two software packages. Such discrepancy is more obvious in the inter-story drift ratio curve than in the roof displacement curve. Similar phenomena can also be found in many other researches [45-47], in which the differences presented in the inter-story drift ratios are more significant than those in the roof displacements. Nonetheless, the overall differences between the simulation results of OpenSees and MSC.Marc are considered acceptable.

Based on the above comparisons, it can be concluded that OpenSees is feasible and reliable for conducting nonlinear analyses of tall RC frame-core tube structures even under strong nonlinear conditions. 


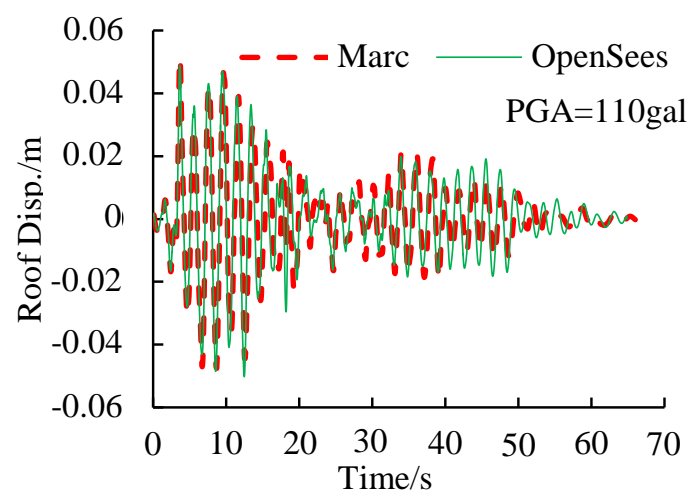

(a) ChiChi 110 gal

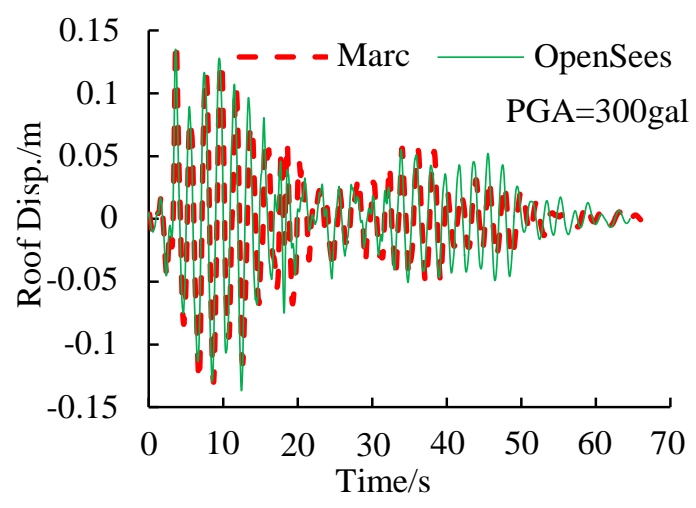

(b) ChiChi 300 gal

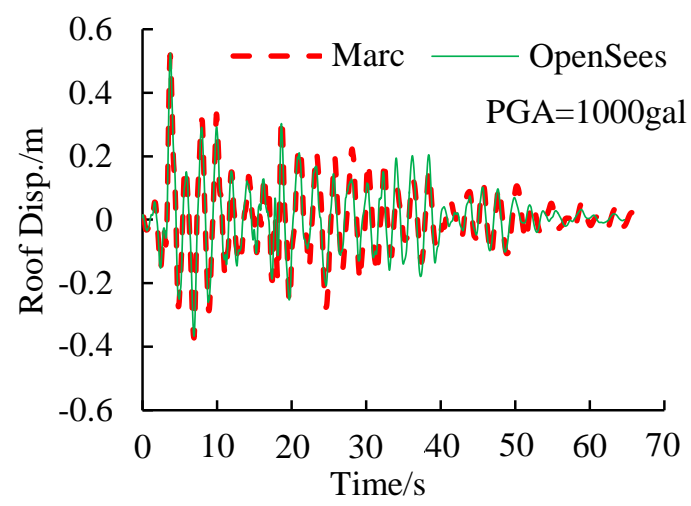

(c) ChiChi 1000 gal 


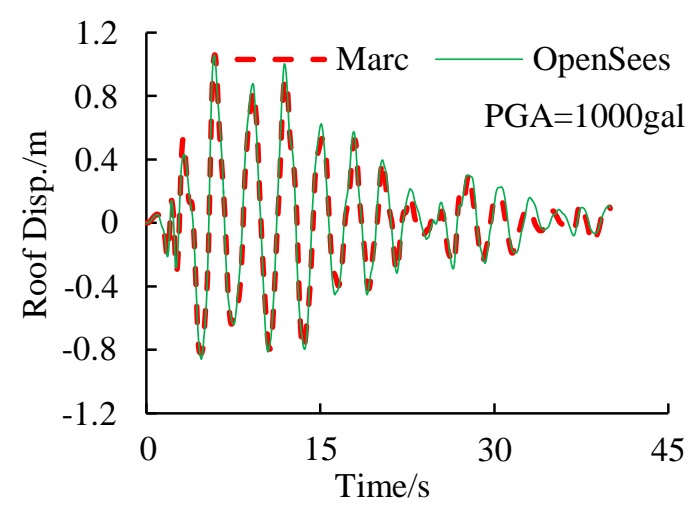

(d) El-Centro 1000 gal

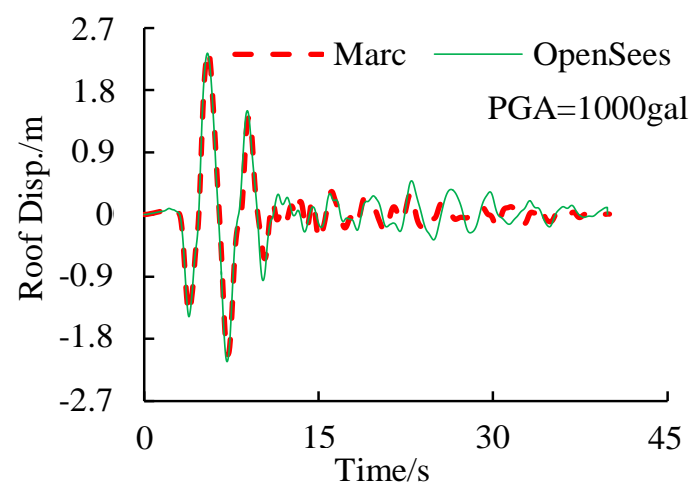

(e) Northridge 1000 gal

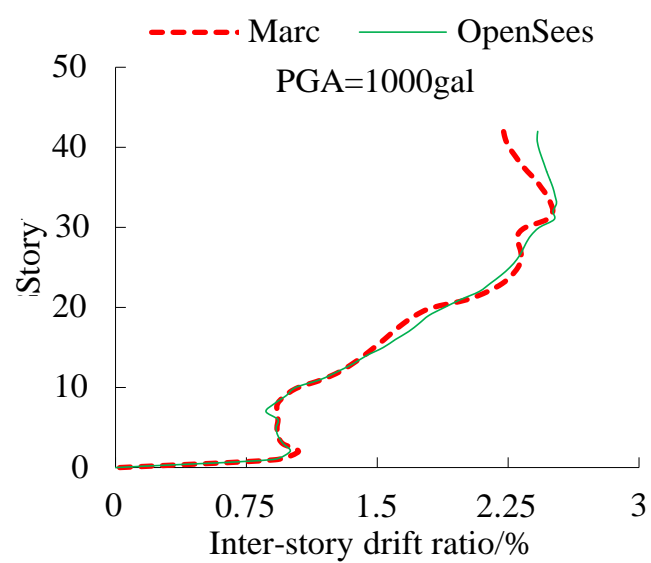

(f) Envelope curves of inter-story drift ratio under 1000 gal Northridge ground motion

Fig. 13. Comparison of the time history analysis results

\subsection{The Shanghai Tower}

The Shanghai Tower is a 124-story multi-functional office building located in Shanghai, China. The total height of the main tower is $632 \mathrm{~m}$. The lateral force 
resisting system of the building is composed of a square RC tube, 12 shaped-steel RC columns and outriggers, defined as a "mega-column/core-tube/outrigger" system. Details of the Shanghai Tower can be obtained from Lu et al. [3].

The design intensity of the Shanghai Tower is 7 degree according to the Chinese code. The corresponding PGA values for earthquakes with $63 \%, 10 \%$ and $2 \%$ of exceedance in 50 years are 35, 100 and 220 gal, respectively. A dynamic analysis with a PGA $=220$ gal is initially conducted. To study the seismic behavior of the Shanghai Tower under an extreme earthquake and further validate the nonlinear computational capacity of the proposed model, a dynamic analysis with a PGA $=400$ gal is also conducted subsequently.

The modeling strategy proposed by Lu et al. [3] is adopted to establish the entire model using MSC.Marc. Subsequently, this model is converted to OpenSees, including 53,006 nodes, 48,774 fiber beam elements defined by 81 fiber H-sections and 39,315 multi-layer shell elements defined by 148 shell sections, as shown in Fig. 14. 


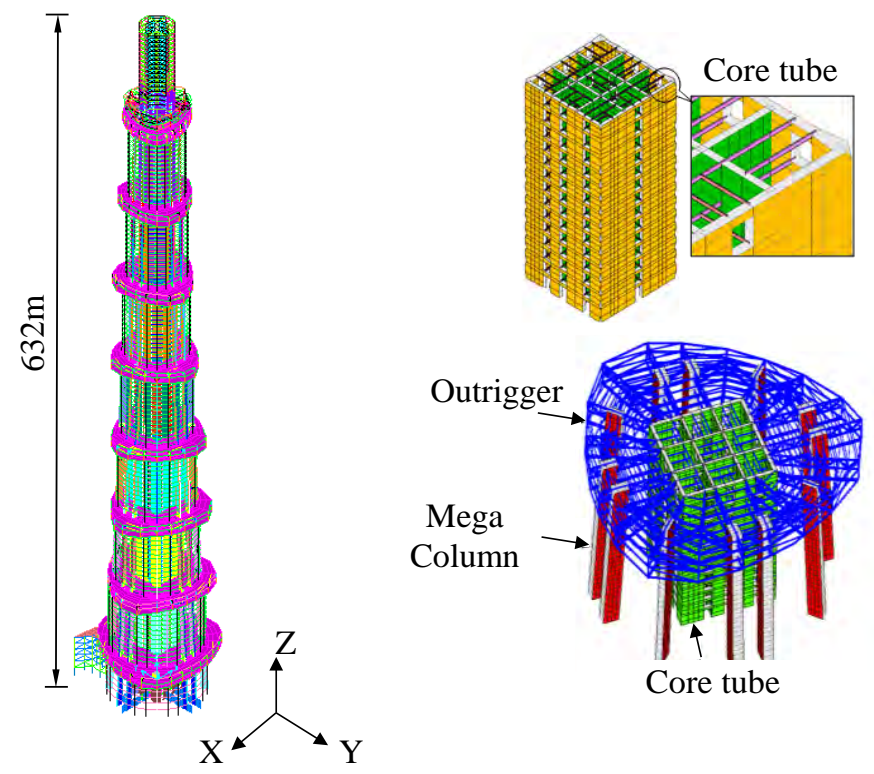

Fig. 14. FE model of Shanghai Tower

Similarly, a gravity analysis and modal analysis are initially conducted; the fundamental periods predicted by MSC.Marc and OpenSees are also found to agree well with each other, with only $1.33 \%$ of difference.

The El-Centro EW ground motion, which is scaled to PGA = 220 gal and 400 gal, is adopted as a typical ground motion input to the structure along the $\mathrm{X}$-axis after conducting the gravity analysis. A 5\% Rayleigh damping ratio is also adopted to perform the nonlinear dynamic time-history analysis. The comparisons of the time-history curves of the roof and the envelope of the inter-story drift curves are illustrated in Fig. 15 and Fig. 16, respectively. Evidently, the results of OpenSees are strongly compatible with those of MSC.Marc. Further, the nonlinear dynamic analysis of Shanghai Tower performed in OpenSees consumes 27.5 hours using the GPU solver, while it takes 24 hours using the parallel CPU solver when the analysis is conducted with MSC.Marc, conclusively validating the feasibility, reliability and efficiency of OpenSees in simulating complex super-tall buildings. 


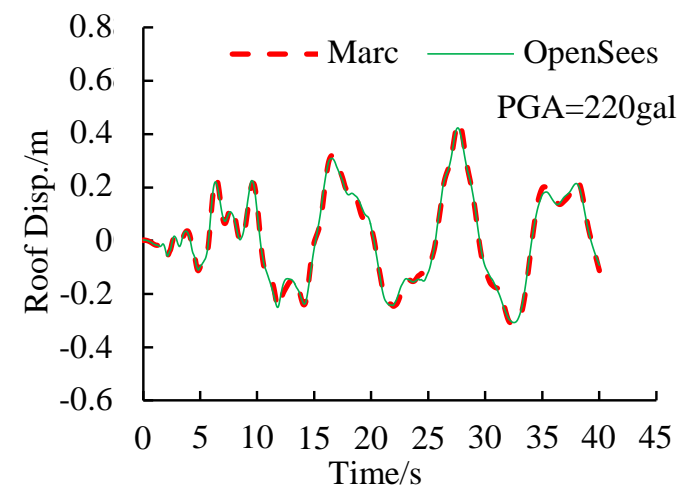

(a) Comparison of the time-roof displacement curves

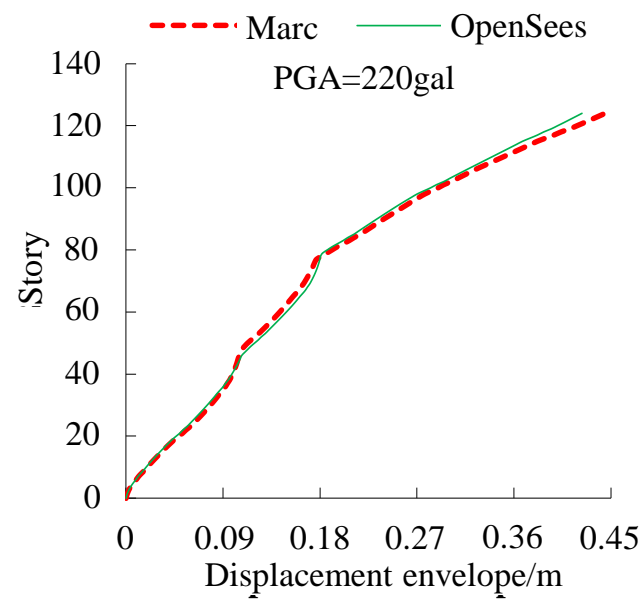

(b) Comparison of the displacement envelope curves of each story

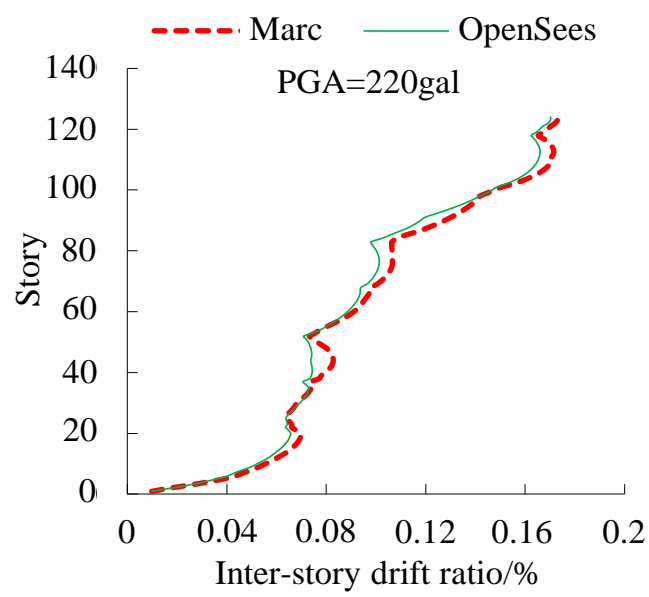

(c) Comparison of the distribution of inter-story drift ratio

Fig. 15. Comparison of the time history analysis results under 220 gal 


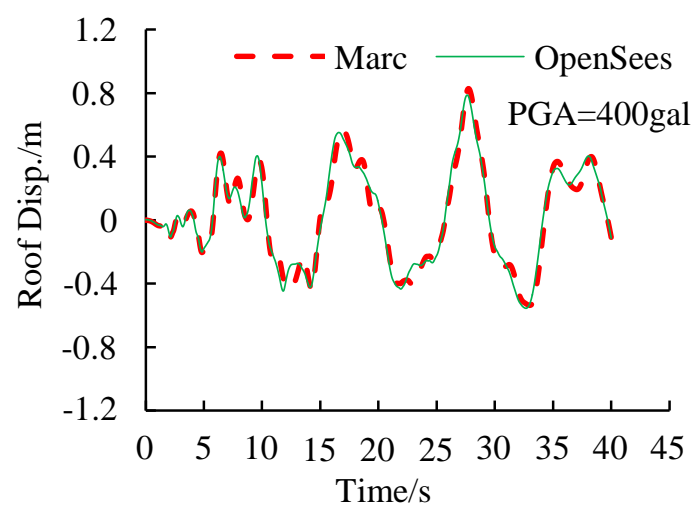

(a) Comparison of the time-roof displacement curves

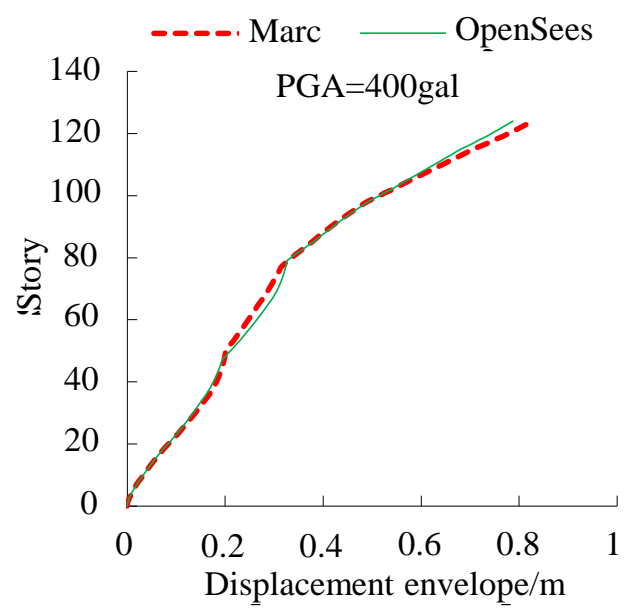

(b) Comparison of the displacement envelope curves of each story

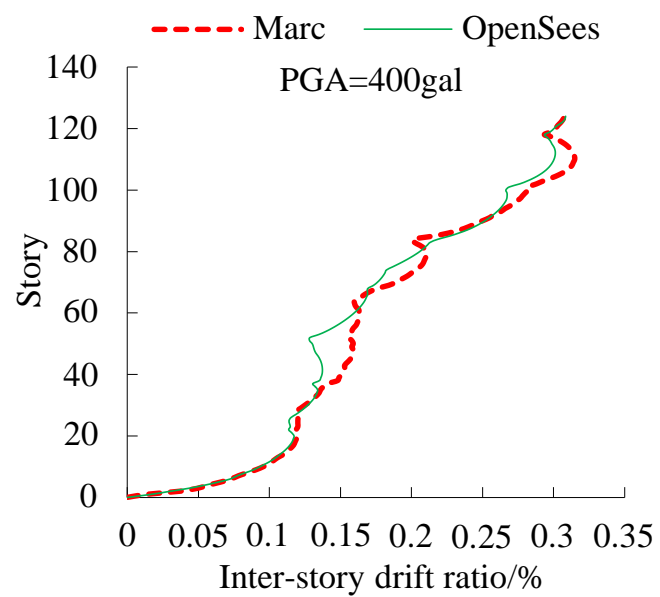

(c) Comparison of the distribution of inter-story drift ratio

Fig. 16. Comparison of time history analysis results under 400 gal

\section{Conclusions}

A new numerical model, viz. the multi-layer shell element, is developed and 
implemented in OpenSees for the simulation of shear walls in super-tall buildings.

A series of shear walls with various types of sections are simulated, through which the reliability and versatility of the new element model is validated. Subsequently, a numerical model system, integrating the fiber-beam elements for beams/columns and the multi-layer shell elements for shear walls/core tubes, is proposed to simulate tall and super-tall buildings using OpenSees. Gravity analysis, modal analysis, pushover analysis and dynamic analysis under specified ground motions of a tall RC frame-core tube building are conducted. A dynamic analysis of an actual super-tall building is also performed. For identical models and analyses, the predicted results of OpenSees and MSC.Marc are compared with close agreement, thus conclusively validating the reliability and rationality of the proposed elements and the analysis method. The research findings of this study will assist in providing an effective tool and a useful reference for further research on the seismic behavior of tall and super-tall buildings based on numerical analysis.

\section{Acknowledgements}

The authors are grateful for the financial support received from the National Key Technology R\&D Program (No. 2013BAJ08B02), the National Natural Science Foundation of China (No. 51222804, 51378299) and the Beijing Natural Science Foundation (No. 8142024).

\section{References}

[1] X. Lu, X.Z. Lu, H. Guan, L.P. Ye, Collapse simulation of reinforced concrete high-rise building induced by extreme earthquakes, Earthquake Engineering \& Structural Dynamics, 42(5) (2013) 
705-723.

[2] X.Z. Lu, X. Lu, H. Guan, W.K. Zhang, L.P. Ye, Earthquake-induced collapse simulation of a super-tall mega-braced frame-core tube building, Journal of Constructional Steel Research, 82 (2013) 59-71.

[3] X. Lu, X.Z. Lu, W.K. Zhang, L.P. Ye, Collapse simulation of a super high-rise building subjected to extremely strong earthquakes, Science China Technological Sciences, 54(10) (2011) 2549-2560.

[4] P.Q. Ren, Y. Li, H. Guan, X.Z. Lu, Progressive collapse resistance of two typical high-rise RC frame shear wall structures, Journal of Performance of Constructed Facilities-ASCE, 2014, DOI:10.1061/(ASCE)CF.1943-5509.0000593.

[5] Q. Jiang, X.Z. Lu, H. Guan, X.G. Ye, Shaking table model test and FE analysis of a reinforced concrete mega-frame structure with tuned mass dampers, The Structural Design of Tall and Special Buildings, 23 (2014) 1426-1442.

[6] Z.W. Miao, L.P. Ye, H. Guan, X.Z. Lu, Evaluation of modal and traditional pushover analyses in frame-shear-wall structures, Advances in Structural Engineering, 14(5) (2011) 815-836.

[7] O. Esmaili, S. Epackachi, R. Mirghaderi, A.A.T. Behbahani, S. Vahdani, Rehabilitation of a high-rise coupled shear wall system in a 56-storey residential reinforced concrete building (Tehran Tower), based on nonlinear dynamic time-history analyses, The Structural Design of Tall and Special Buildings, 20(8) (2011) 1035-1047.

[8] D. Poon, L. Hsiao, Y. Zhu, L. Joseph, S. Zuo, G. Fu, Ihtiyar, Non-linear time history analysis for the performance based design of Shanghai Tower, Structures Congress, (2011) 541-551.

[9] H.J. Jiang, B. Fu, L. Liu, X.W. Yin, Study on seismic performance of a super-tall steel-concrete hybrid structure, The Structural Design of Tall and Special Buildings, 23(5) (2014) 334-349.

[10] X.L. Lu, N.F. Su, Y. Zhou, Nonlinear time history analysis of a super-tall building with setbacks in elevation, The Structural Design of Tall and Special Buildings, 22(7) (2013) 593-614.

[11] G. Michaloudis, G. Blankenhorn, S. Mattern, K. Schweizerhof, Modeling structural failure with finite element analysis of controlled demolition of buildings by explosives using LS-DYNA, High Performance Computing in Science and Engineering'09. Springer Berlin Heidelberg, (2010) $539-551$.

[12] Marc MSC, Volume A, Theory and user information, MSC Corp, 2007.

[13]B. Patzák, Z. Bittnar, Design of object oriented finite element code, Advances in Engineering 
Software, 32(10) (2001) 759-767.

[14] Y.J. Park, A.M. Reinhorn, S.K. Kunnath, IDARC: Inelastic damage analysis of reinforced concrete frame-shear-wall structures, Department of Civil Engineering State University of New York at Buffalo, 1987.

[15] S. Mazzoni, F. McKenna, M.H. Scott, G.L. Fenves, OpenSees command language manual, Pacific Earthquake Engineering Research (PEER) Center, 2006.

[16]F. McKenna, M.H. Scott, G.L. Fenves, Nonlinear finite-element analysis software architecture using object composition, Journal of Computing in Civil Engineering, 24(1) (2009) 95-107.

[17] J.W. Wallace, Modelling issues for tall reinforced concrete core wall buildings, The Structural Design of Tall and Special Buildings, 16(5) (2007) 615-632.

[18] Y. Li, X.Z. Lu, H. Guan, L.P. Ye, An improved tie force method for progressive collapse resistance design of reinforced concrete frame structures, Engineering Structures, 33(10) (2011) 2931-2942.

[19] E.N. Dvorkin, D. Pantuso, E.A. Repetto, A formulation of the MITC4 shell element for finite strain elasto-plastic analysis, Computer Methods in Applied Mechanics and Engineering, 125(1) (1995) 17-40.

[20] P. Hallinan, H. Guan, Layered finite element analysis of one-way and two-way concrete walls with opening, Advances in Structural Engineering, 10 (1) (2007) 55-72.

[21]H. Guan, Y.C. Loo, Flexural and shear failure analysis of reinforced concrete slabs and flat plate, Advances in Structural Engineering, 1 (1997) 71-85.

[22] Y.C. Loo, H. Guan, Cracking and punching shear failure analysis of RC flat plates, Journal of Structural Engineering, 123(10) (1997) 1321-1330.

[23]K.E. Løland, Continuous damage model for load-response estimation of concrete, Cement and Concrete Research, 10(3) (1980) 395-402.

[24] J. Mazars, A description of micro-and macro-scale damage of concrete structures, Engineering Fracture Mechanics, 25(5) (1986) 729-737.

[25] J.G. Rots, P. Nauta, M.A. Kusters, J. Blaauwendraad, Smeared crack approach and fracture localization in concrete, HERON, 30(1) (1985) 1-48.

[26] J.G. Rots, J. Blaauwendraad, Crack models for concrete: discrete or smeared? Fixed, multi-directional or rotating?, HERON, 34(1) (1989) 1-59.

[27] Z.P. Bazant, Size effect in blunt fracture: concrete, rock, metal, Journal of Engineering Mechanics, 
110(4) (1998) 518-535.

[28] M. Jirásek, M. Bauer, Numerical aspects of the crack band approach, Computers \& Structures, 110 (2012) 60-78.

[29] X.L. Lu, Y. Zhou, J.H. Yang, J. Qian, C. Song, Y. Wang, Shear Wall Database, Network for Earthquake Engineering Simulation (database), Dataset, 2010.

[30] Q. Chen, Static inelastic analysis of reinforced concrete coupled shear wall, Ph.D. Thesis, Tsinghua University, Beijing, China, 2002.

[31] X.L. Lu, Y.T. Chen, Modeling of coupled shear walls and its experimental verification, Journal of Structural Engineering, 131(1) (2005) 75-84.

[32] D.S. Huang, W.X. Cheng, Study on elasto-plastic performances of shear walls with short piers, Journal of Southeast University (Natural Science Edition), 33(2) (2003) 164-167.

[33] J.B. Mander, M.J. Priestley, R. Park, Theoretical stress-strain model for confined concrete, Journal of Structural Engineering, 114(8) (1988) 1804-1826.

[34] F.C. Filippou, E.P. Popov, V.V. Bertero, Effects of bond deterioration on hysteretic behavior of reinforced concrete joints, Report EERC 83-19, Earthquake Research Center, University of California, Berkeley, 1983.

[35] E. Spacone, F.C. Filippou, F.F. Taucer, Fiber beam-column model for non-linear analysis of R/C frames: Part I. Formulation, Earthquake Engineering and Structural Dynamics, 25(7) (1996) 711-726.

[36] P. Martinelli, F.C. Filippou, Simulation of the shaking table test of a seven-story shear wall building, Earthquake Engineering \& Structural Dynamics, 38(5) (2009) 587-607.

[37] B.F. Maison, K. Kasai, G. Deierlein, ASCE-41 and FEMA-351 Evaluation of E-Defense collapse test, Earthquake Spectra, 25(4) (2009) 927-953.

[38] A. Kidarsa, M.H. Scott, C.C. Higgins, Analysis of moving loads using force-based finite elements, Finite Elements in Analysis and Design, 44 (2008) 214-224.

[39] A. Zona, G. Ranzi, Finite element models for nonlinear analysis of steel-concrete composite beams with partial interaction in combined bending and shear, Finite Elements in Analysis and Design, 47 (2011) 98-118.

[40] J. Moehle, Y. Bozorgnia, N. Jayaram, Case Studies of the Seismic Performance of Tall Buildings Designed by Alternative Means: Task 12 Report for the Tall Buildings Initiative: Final Report to 
California Seismic Safety Commission and California Emergency Management Agency, Pacific Earthquake Engineering Research Center, 2011.

[41]X.Z. Lu, M.K. Li, H. Guan, X. Lu, L.P. Ye, A comparative case study on seismic design of tall RC frame-core tube structures in China and USA, The Structural Design of Tall and Special Buildings, 2015. DOI: 10.1002/tal.1206.

[42] URL: http://www.luxinzheng.net/download/OpenSeesTHU.zip; Date Accessed: June 2014.

[43] JGJ 3-2010, Technical specification for concrete structures for tall building, Beijing: Ministry of Housing and Urban-Rural Development of the People's Republic of China, 2010 [in Chinese].

[44] A.K. Chopra, Dynamics of structures, Vol. 3. New Jersey: Prentice Hall, 1995.

[45] M.E. Rodríguez, J.I. Restrepo, J.J. Blandón, Shaking table tests of a four-story miniature steel building-model validation, Earthquake Spectra, 22(3) (2006) 755-780.

[46] P. Martinelli, F.C. Filippou, Simulation of the shaking table test of a seven-story shear wall building, Earthquake Engineering and Structural Dynamics, 38 (2009) 587-607.

[47] D.G. Lignos, Y. Chung, T. Nagae, M. Nakashima, Numerical and experimental evaluation of seismic capacity of high-rise steel buildings subjected to long duration earthquakes, Computers \& Structures, 80 (2011) 959-967.

\section{Appendix A. Command lines to implement the multi-layer shell element in OpenSees}

The two-dimensional concrete material is introduced to the model through the following command lines as:

nDMaterial PlaneStressUserMaterial \$matTag 407 \$fc \$ft \$fcu \$epsc0 \$epscu \$epstu \$stc

$\begin{array}{ll}\text { \$matTag } & \text { integer tag identifying material } \\ \mathbf{\$ f c} & \text { concrete compressive strength (positive) } \\ \mathbf{\$ f t} & \text { concrete tensile strength (positive) } \\ \mathbf{\text { \$fcu }} & \text { concrete crushing strength (negative) } \\ \mathbf{\text { Sepsc0 }} & \text { concrete strain at maximum strength (negative) } \\ \mathbf{\text { Sepscu }} & \text { concrete strain at crushing strength (negative) } \\ \mathbf{\text { \$epstu }} & \text { ultimate tensile strain (positive) }\end{array}$


nDMaterial PlateFromPlaneStress \$newmatTag \$matTag \$OutofPlaneModulus

$\begin{array}{ll}\text { \$newmatTag new integer tag identifying material deriving from pre-defined } \\ \text { PmatTag } & \text { PlaneStressUserMaterial } \\ \text { \$OutofPlaneModulus shear modulus of out plane }\end{array}$

The reinforced steel material for the multi-layer shell element is introduced to the model through a command line as:

nDMaterial PlateRebar \$newmatTag \$matTag \$sita

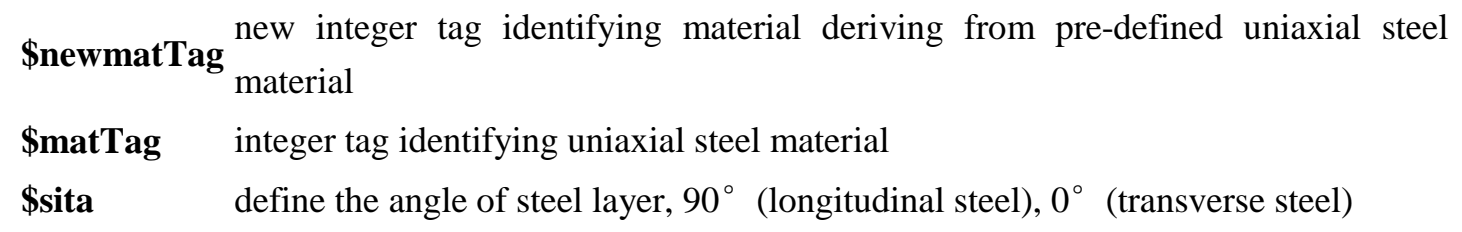

The multi-layer shell section is defined by the following command line as: section LayeredShell \$sectionTag \$nLayers \$matTag1 \$thickness1...\$matTagn \$thicknessn

\$sectionTag unique tag among sections

\$nLayers total numbers of layers

\$matTag1 material tag of first layer

\$thickness1 thickness of first layer

...

\$matTagn material tag of last layer

\$thicknessn thickness of last layer 